\title{
Integrity in the fresh produce supply chain: solutions and approaches to an emerging issue
}

\author{
by Manning, L. and Monaghan, J.M.
}

Copyright, Publisher and Additional Information: This is the authors' accepted manuscript. The final published version (version of record) is available online via Taylor and Francis

Please refer to any applicable terms of use of the publisher.

DOI: https://doi.org/10.1080/14620316.2019.1574613

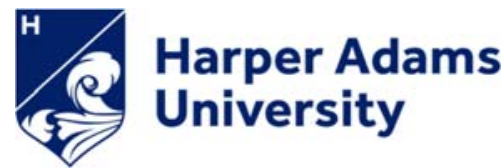

Manning,L. and Monaghan, J.M. 2019. Integrity in the fresh produce supply chain: solutions and approaches to an emerging issue. Journal of Horticultural Science \& Biotechnology. 


\section{Integrity in the fresh produce supply chain: solutions and approaches \\ 2 to an emerging issue.}

3 Manning, Louise. and Monaghan, James

4

Food fraud is the misrepresentation of food in terms of labelling or documentation. The fresh produce supply chain is global with fresh produce grown many thousands of miles from the point of purchase and consumption. Long supply and complex fresh produce supply chains provide opportunity for fraudulent activity to occur especially further processing or re-packing of products to mask opaque practice and non-compliant behaviour. Price premiums for products designated as 'high-value', for example, organic produce, produce of particular provenance, or geographical production area provides motivation for less scrupulous actors to present for sale, produce that is mislabelled or misrepresented. People integrity as well as data, product and process integrity are gaining wider attention in the horticultural sector. Types of fraud critiqued in this review paper include mislabelling, substitution or misrepresentation of origin (country or regional location), method of production (organic or conventional) or incorrect varietal declaration. These challenges and the existing and emerging technologies that are both used within a quality assurance programme and alternatively used by regulators when investigating potential instances of fraudulent behaviour are considered. New methodological solutions and approaches are emerging and such techniques will develop rapidly to meet the growing challenge of fraud and to ensure consumer trust in the industry is maintained especially as types of food fraud evolve and become more sophisticated.

Keywords: produce, integrity, food fraud, substitution, provenance 


\section{Introduction}

Food fraud is the misrepresentation of food in terms of labelling or documentation i.e. the food is not what it is purported to be. Fraudulent mis-description on food product labels is a widespread problem, particularly with high added-value products commanding a premium price (Woolfe and Primrose, 2004:222). Food fraud is 'deliberately placing food on the market, for financial gain, with the intention of deceiving the consumer' (Elliott Review, 2013). Food fraud can lead to food safety issues, but in the food industry food fraud is increasingly seen as a different challenge to food safety problems. This means that in order to reduce the likelihood of occurrence and also to reduce the impact should an incident occur countering the risk of food fraud requires both similar and alternative methods to those that are currently used to address food safety risk.

The types of fraud critiqued in this review paper include mislabelling, substitution or misrepresentation of origin (country or regional location), method of production (organic or conventional) or incorrect varietal declaration. The aim of this work is to consider the challenges and the existing and emerging technologies that are both used within a quality assurance programme and alternatively used by regulators when investigating potential instances of fraud. Fresh produce sold in the European Union $(E U)$ is of particular interest here because of the need for market compliance with EU ten specific marketing standards for ten types of fresh producec where criteria such as class (quality attribute), variety and country of origin must be truthfully ascribed (Gov.uk, 2019). Thus, there is a clear financial motivation for perpetrators of fraud to substitute alternative products with different varietal attributes or geographic origin where existing quality control methods would find it difficult to identify that such substitution has taken place. In the years 2016-18 there were fifty-nine notification for fruit and vegetables for "adulteration/fraud" within the Rapid Alert System for Food and Feed (RASFF) Database 
53 linked to problems such as illegal importing, absence of health certificate(s), Common

54 Entry Documents (CED) and certified analysis reports and improper health certificates that were signed before the analysis was performed (Source: RASFF, nd). Examples of non-compliant products included dried figs from Turkey; frozen okra, curry leaves and red chilli from India; raisins from Iran and Turkey; dried beans and watermelon seeds from Nigeria; fenugreek from Ethiopia, dragon fruit from Vietnam, and peppers from Egypt.

Global supply chains are becoming more sophisticated and complex, and together with the potential for weak governance, this means that the low probability of discovery or the low severity of punishment or sanctions provides an incentive for perpetrators to commit food fraud (Sarpong, 2014; Pustjens et al. 2016). However, food fraud may also be motivated as a mechanism to appear to meet stated customer (retailer or food service) requirements e.g. substituting ingredients to meet supply chain constraints and barriers (Kowalska et al. 2018). The constraints and barriers identified in the literature that drive this mendacious behaviour include, first, regulatory or political pressures, and then supply chain pressures. These supply chain pressures include: economic, competitive or coercive dynamics; information asymmetry with associated power concentration with specific actors; data swamping, opacity i.e. a lack of visibility; or organisations being time poor and looking for quick solutions to deliver value in the supply chain (Manning, 2016; Manning et al. 2017). Indeed, reasons for mislabelling of fresh produce whether intentional or unintentional might be due simply to human error, a lack of verification during product labelling changes in production system or even an error in original artwork design (Kowalska et al. 2018). Changes in the fresh produce supply chain that increase vulnerability and risk include: globalisation, especially where horticultural production takes place in countries with lower regulatory standards and governance; more 
prescriptive food safety management standards; the impacts of climate change on supply and demand dynamics; and transitions in food culture and consumer behaviour (Kleter and Marvin, 2009; Jacxsens et al. 2010; Marvin et al. 2016) Further factors that influence fresh produce chains have been synthesized (Table 1).

\section{Take in Table 1}

It is arguable that, to date, fresh produce food safety has had a higher profile than inadequate production practices being linked to foodborne illness outbreaks (FIOs).

These FIOs can be large, with fresh produce accounting for $10 \%$ of FIOs in the European Union from 2007 to 2011, 26\% of individual illness cases, $35 \%$ of hospitalisations, and $46 \%$ of deaths (EFSA, 2013). In response, production standards have been developed that follow the principles of hazard analysis and critical control point (HACCP) systems and apply a systems-based approach to managing food safety (Gil et al. 2015; Monaghan et al. 2017). Growers are required by many customers to adhere to a quality assurance scheme (QAS), either an industrywide QAS such as Red Tractor Assurance (RTA, 2017) or a customer-specific QAS such as McDonald's good agricultural practices (GAP) guidelines (McDonald's Corp., 2012). However, these systems rely heavily on a formalised system to show that actions are being completed and as a result there is a difference between developing and developed countries in the efficacy of food safety control systems employed (Faour-Klingbeil and Todd, 2018)

Food integrity has been defined as ensuring that food which is offered for sale is

99 not only safe and of the nature, substance and quality expected by the purchaser, but also 100 considers other aspects of food production, such as the way it has been sourced, procured 101 and distributed and being honest about those elements to consumers (Elliott, 2014). Thus, 102 developing supply chain systems and standards that assure food integrity will enhance 
103 food safety, authenticity, quality, and increase consumer trust in product claims (Kleboth

104 et al. 2016; Goddard et al. 2018). Integrity in the horticulture supply chain is driven by

105 consumers who demand that the produce they purchase is firstly, what it purports to be

106 (product integrity); secondly is produced in line with defined standards (process

107 integrity); thirdly that these standards address ethical corporate behaviour (people

108 integrity); and finally the data associated with the produce (data integrity) is valid and

109 reflects the intrinsic and extrinsic characteristics of the product (Manning, 2016;

110 Manning, 2018). Thus developing product integrity and traceability protocols can

111 underpin product integrity, trust and an open and transparent supply network (Soon et al.

112 2019).

113 The differentiation of fresh produce as previously described at the production and

114 retail level provides opportunity for certain types of food fraud such as economically

115 motivated substitution or mislabelling to occur. Economically motivated substitution

116 could also happen when produce from one country of origin is substituted for another

117 product from a different source especially if the produce is visually similar and there is a

118 large price differential between the produce from the claimed source and the source being

119 substituted. Further, the additional value derived in differentiating between

120 conventionally grown products and organic production means that there is an

121 economically motivated opportunity to substitute conventional for organic produce and

122 label this as organic. Examples of reported cases of mislabelling and misrepresentation

123 have been collated to show the types of fraud that can occur (Table 2).

$124 \quad$ Take in Table 2

125 Product identity from source through to processing/packing and distribution has

126 been aligned with notions of traceability (Bertolini et al. 2006); a so-called 'chain of

127 custody' (Thakur and Hurburgh, 2009). Indeed identity preservation is becoming an 
128 increasingly important credence or process attribute that adds economic value to a product

129 (Dabbene et al. 2014). Regulation EC/178/2002 defines traceability as the ability to trace

130 and follow a food, feed, food-producing animal or substance intended to be, or expected

131 to be incorporated into a food or feed, through all stages of production, processing and

132 distribution. In high information input and complex supply chains such as fresh produce,

133 the market requirements for identity preservation and traceability often need to exceed

134 the legislative requirements for 'one step back-one step forward' processes (Manning,

135 2017). Thus, an effective traceability system should establish and enable the identification

136 of product lots and their relation to batches of raw materials, processing and delivery

137 records (BS EN ISO 22000:2005).

138 Industry mechanisms to ensure that identity preserved products are what they are

139 purport to be include the use of business to business (B2B) or business to consumer (B2C)

140 supply chain standards. B2C standards through associated cues on packaging such as

141 organic certification logos, geographic indication [British flag or country of origin

142 designation], method of production [Red Tractor] and the associated traceability and mass

143 balance checks i.e. extrinsic product characteristics, need to be verified in order to ensure

144 consumer trust (Manning and Soon, 2014). Whilst some of these transactional tools are

145 private mechanisms, legislative standards in the European Union (EU) also underpin the

146 use of the term 'organic' or provenance designated geographic origin (EU Protected Food

147 Name Scheme via the requirements of Regulation EU No 1151/2012).

148 This review paper considers specifically food fraud in the fresh produce supply

149 chain and the existing and emerging product and process verification activities that take

150 place. The British Retail Consortium (BRC, 2018) Global Food Standard describes

151 verification as the application of methods, procedures, tests and other evaluations, in

152 addition to monitoring, to determine whether a control or measure is or has been operating 
153 as intended. Process verification is the assessment of objective evidence that relates to

154 process integrity such as the assessment of documentation, product and process

155 certification and traceability data rather than product testing. However, process

156 verification, such as third party certification (TPC) relies upon the ability to assess valid,

157 authentic, objective and representative evidence (Manning and Soon, 2014). Product

158 verification involves the analysis and testing technologies used both within a quality

159 assurance programme and by regulators when investigating potential instances of

160 fraudulent behaviour.

161 2. Process verification: the role of auditing

162 An audit is the systematic, independent and documented process undertaken to obtain

163 and then evaluate valid, representative, objective evidence (records, statements of fact or

164 other information) to determine whether the evidence demonstrates that audit criteria

165 (policies, procedures and requirements) and standards have been fulfilled (BS EN ISO

166 9001: 2015). Therefore, auditing is an effective form of verification when it identifies

167 both conformity and any deviations from standards, legislation or regulation whilst

168 trading this outcome against using the minimum amount of resources to achieve the audit

169 objectives (Kleboth et al, 2016). In a transactional way, the industry often sees audits as

170 being of value when they are quick yet accurate, sometimes referred to as a snapshot,

171 independent, objective, unbiased, transparent, reliable, scalable and as a result promote

172 consensus building (Albersmeier et al. 2009; Salama et al. 2009; Powell et al. 2013).

173 However, TPC audits, a key element of process verification activities in the supply chain,

174 are a market interaction and there is a risk that this economic framing could impact on

175 independence and validity (Martinez et al. 2013; Verbruggen and Havinga, 2015). The

176 Elliott Review (2013) noted that the quality and completeness of TPC audits was variable

177 and that there is a danger that an audit regime can be used for raising revenue, placing 
178 unnecessary costs on food businesses. TPC audits alone will not deliver effective

179 verification of integrity in the food supply chain and they need to be undertaken in co-

180 ordination with other activities such as product testing.

181 One challenge to the efficacy of TPC and even first party or second party audits as a

182 form of verification is the degree of data integrity. Data integrity, quite simply, is the

183 quality of data i.e. the degree of accuracy, consistency or validity of data held by an

184 organisation or multiple organisations in the food supply chain. This data is either hard

185 form (paper based) or digital form contained on computers, networks and clouds. Whilst

186 the increased ability to store information might improve timeliness for process and

187 product verification, conversely the volume of data being held can lead to data swamping

188 for supply chain organisations, regulators and certification bodies undertaking third party

189 verification (Manning et al. 2017; Manning and Wareing, 2018). Data swamping arises

190 as a result of the sheer volume of data being collected and stored, the inefficient control

191 or storage of data either as a result of strategic weakness or because of the cost of

192 implementing digital solutions, or simply a misunderstanding of the timeline for data to

193 be collected and then shared with others. There is no current literature on the challenge

194 of data swamping or indeed the effective management of data in the food literature

195 suggesting this is an area for future empirical research. In this context, data management

196 can be considered as the actions taken, and governance implemented, to ensure data

197 integrity when an organisation acquires, validates, stores and shares data.

198 One technological solution put forward to address data integrity and data management

199 is the use of distributed ledger technology, with one option being Blockchain. The

200 proposed advantages of this type of technology are reduced cost and increased speed of

201 transactions in the supply chain, more effective incident identification and

202 responsiveness, and the ability to overcome information asymmetry especially for 
consumers and as a result improving inter-actor trust and transparency (Manning and

204 Wareing, 2018). The disadvantages are the need for strong governance of systems to 205 prevent cyber-security breaches. The nature and type of cyber threats is increasing and

206 shifting rapidly in line with the use of digital data technology and the risk of infiltration 207 of digital networks (Khursheed et al. 2016).

208 Hollands et al. (2018) consider the benefits and challenges associated with 209 Blockchain and argue that traceability systems are already a core strategic process within 210 many food company management systems that control products and manage supply chain

211 data especially through enterprise resource planning (ERP) platforms. However they 212 counter ERP systems are expensive to implement and Blockchain technology may 213 provide the opportunity to link "blocks of information" associated with distinct 214 transactions that can form a tracking and tracing system. The IBM platform "Food Trust" 215 has been used to trace mangoes to source in seconds superseding the one step forward 216 one step back systems mentioned earlier in this paper. However Bateman and Cottrill 217 (2017) suggest that there are challenges to the use of Blockchains, distributed ledgers, 218 especially if the data is of poor quality that is entered into the system especially where 219 the data them becomes immutable. They further argue that not all members of the supply 220 chain have digital access especially smallholders in developing countries so this can mean 221 that some data is still recorded manually before later being entered into a system. There 222 is still a risk too of fraudulent behaviour where incorrect data is intentionally entered into 223 the system.Thus, data integrity and associated management and security protocols need 224 to be more actively developed and verified in fresh produce supply chains to reduce the 225 potential for both intentional and unintentional mislabelling incidents.

\section{Product verification: testing technologies}


An alternative approach to audits for establishing product attributes is to test the 228 produce for its innate integrity. When determining an appropriate testing technology the 229 first consideration is whether the technology is using a targeted or a non-targeted method.

230 Targeted methods are seeking to identify the presence or alternatively absence of specific 231 markers that can demonstrate i.e. authenticate the identity of a given food or identify the 232 presence of a given chemical or contaminant. Non-targeted methods are used as a wider 233 screening mechanism for food. Ballin and Laursen (2018) in a review of analytical 234 approaches for food authentication have proposed definitions and nomenclature for 235 targeted and non-targeted approaches. Targeted analysis focusses on one or more pre236 defined analytical target(s) e.g. a specific pesticide residue. Non-targeted analysis, 237 simultaneously detects numerous unspecified targets or data points (often>100) and is 238 often qualitative e.g. 'fingerprinting' or metabolomics (Ballin and Laursen, 2018).

239 Difficulties in developing authenticity methodology include finding appropriate markers

240 that characterise an element of the food that is consistent and can be measured accurately 241 and having authentic samples that can assist methodology development in the first place 242 (Primrose et al. 2010). Chemical methods to determine authenticity include primary 243 metabolites such as sugar, amino acid and/or organic acid profiles of certain fruits (Bat et 244 al. 2018). However, they argue secondary metabolites are influenced by geographic origin 245 and production methods. Proving fraud has taken place requires detailed detection 246 techniques (Woolfe and Primrose. 2004) and studies deploying DNA markers to identify 247 mislabelling of plant-derived products are limited (Scarano et al. 2015). Fresh produce 248 can be characterised using 'classical techniques' such as the use of isotope ratio mass 249 spectrometry. Increasingly, new technologies are superseding and complementing these 250 techniques. The majority of these constitute the so-called 'omic' technologies where high 251 throughput analyses are combined with chemometrics and bioinformatics 

origin i.e. is the correct variety named; is the geographic origin of the crop correctly identified; have unapproved/illegal pesticides been applied; is the crop 'wild harvested'; is the crop 'organic'; (Esslinger et al. 2014). Different approaches are considered here that address these issues and provide data where authenticity, identity or provenance and regulatory compliance can be determined.

\subsection{Variety testing}

DNA analysis techniques have developed to identify species or variety include

260 detection of single nucleotide polymorphisms (SNPs), simple sequence length

261 polymorphisms (SSLPs), restriction fragment length polymorphisms (RFLPs), and the

262 use of real-time polymerase chain reaction (PCR) and heteroduplex analysis (Woolfe and 263 Primrose, 2004; Primrose et al. 2010). Identification techniques based on PCR amplification followed by simple sequence repeats (SSR) analysis and principal coordinate analysis (PCA) can identify genetic differences in varieties of tomatoes especially in processed products where morphological markers may be lost (Scarano et al. 2015). SSR techniques have also been used for variety identification, genetic fingerprinting, genetic diversity analysis and parentage verification in Prunus species, but specifically sweet cherry (Liu et al. 2018). However, the level of DNA may not reflect accurately the amount of material originally substituted or added especially if processing

271 has degraded the DNA or there are multiple copies of a given gene sequence in a cell 272 (Primrose et al. 2010).

\subsection{Geographic origin}


2015), but the geographic origin of produce can be difficult to quantify. Isotope

277 abundances can vary with the geographic location, and if samples of the soil or water are

278 available from geographical regions, it may be possible to identify material grown in that

279 area. For example, it was possible to discriminate between peppers of different 280 geographical origin by correlating the $\delta^{18} \mathrm{O}$ of water in the peppers with a database of

281 isotope ratios for water (Flores et al. 2013). Another approach is to use elemental 282 fingerprinting (Danezis et al. 2016) where the profile of groups of macro elements, trace 283 elements, rare earth elements and ultra-trace elements can be used as an indicator of 284 geographical origin as the profiles are linked to the geology of the production area 285 (Danezis et al., 2016). Perini et al. (2018) conclude from their studies on soft fruit that

286 the $\delta^{13} \mathrm{C}$ and $\delta^{15} \mathrm{~N}$ value of pulp and the $\delta^{18} \mathrm{O}$ of juice can be used to differentiate 287 geographical origin and verify declared provenance. In addition, microbial populations may differ between geographical locations and El Sheika et al. (2009) analysed the yeast community structures on the surface of Physalis and successfully discriminated between geographical production areas.

\subsection{Misrepresented use of pesticides}

Fresh produce monitoring programmes by retailers and enforcement agencies target residue testing towards levels of specific compounds either the active ingredient or

294 the associated breakdown products. Multi-residue analysis methods commonly use gas or liquid chromatography coupled with mass spectrometry (GC/LC-MS) (Stachniuk, 2018). Residue testing has two uses: it can establish whether label recommendations have

297 been followed i.e. Good Agricultural Practice (GAP); and whether residues are present of non-approved or illegal pesticides. However, the approach has limitations as residues decline over time and early application of non-approved compounds may mean residues are undetected at reportable levels. 
It is possible to detect the accumulation of synthetic $\mathrm{N}$ fertiliser in plant tissues by

303 looking at stable isotope ratios in the produce in a targeted approach. Crops grown

304 organically have $\delta^{15} \mathrm{~N}$ values of +0.3 to $+14.6 \%$, while crops grown with synthetic $\mathrm{N}$

305 fertiliser range from negative to positive values, i.e. -4.0 to $+8.7 \%$ (Inácio et al. 2015).

306 However, a number of studies have highlighted the weaknesses in this approach where

307 the organic and conventional values can overlap e.g. Schmidt et al. (2005) reported that

308 lettuce, onions, cabbage and Chinese cabbage from field production had $\delta^{15} \mathrm{~N}$-values in

309 the range of +5 to +6 for conventional production and +5.5 to $+7.5 \%$ for organic

310 production. In addition, the application of a small amount of manure or the use of water

311 with a large concentration of nitrate can result in an increase of the $\delta^{15} \mathrm{~N}$ values, close to

312 those obtained in organic production (Laursen et al. 2014). On its own, $\delta^{15} \mathrm{~N}$ data can only

313 provide supporting evidence in suspected fraud cases, but not for discriminating between

314 both production systems (Bueno et al. 2018).

\subsection{Substitution of conventionally grown produce as organic.}

316 Studies have suggested using multiple isotopes of nitrate derived $\mathrm{N}$ and $\mathrm{O}$

317 (Laursen et al. 2013; Mihailova et al. 2014). Approaches based on the measurement of

318 multiple biomarkers and/or complex chemical or physical profiles/fingerprints supported

319 by multivariate statistical analysis show more potential (Capuano et al. 2013). Bueno et

320 al. (2018) demonstrated that a combined chemo-metric analysis of high-resolution

321 accurate mass spectrometry (HRAMS) and $\delta^{15} \mathrm{~N}$ data was able to discriminate

322 successfully between organic and conventionally grown tomatoes. Multivariate analysis,

323 combining isotope data with mineral content (Yuan et al. 2018), and mineral content and

324 key metabolites (Flores et al. 2013) have been able to classify organic and conventional 325 brassica, peppers and lettuce. 
Studies have found that organic methods of vegetable production have increased concentration of total glucosinolates and benzylglucosinolate which can be used to differentiate methods of cultivation (Rossetto et al. 2013); and major and trace element profiling has been used to determine whether onions and peas were conventionally or organically grown (Gundersen et al. 2000). Bioactive components such as phenolic and hydrophilic antioxidant capacity were identified as markers for being able to determine organic and conventional tomato juices (Vallverdú-Queralt et al. 2012).

Trace element and nitrogen isotope data is of value in differentiating conventional and organic tomatoes but less effective with lettuce indicating a concern over analytical testing being used in isolation as a single determinant of provenance (Kelly and Bateman, 2010). Picchi et al. (2012) urged caution that phytochemical content as a marker for considering a crop's response to growing methods, in this case cauliflower, was affected by genotype i.e. some genotypes showed improved phytochemical content under organic production and others particularly with regard to glucosinolates and ascorbic acid did not. Conventional and organic production influence the external microbial populations and internal metabolite production. There is a significant focus on the use of

342 metabolomics (metabolite fingerprinting) to discriminate between production systems 343 using both targeted and non-targeted approaches (Cubero-Leon, 2014; Medina et al. 344 2019). Bigot et al. 2015 analysed the yeast and bacterial community profiles on the 345 surface of nectarines and peaches using PCR-DGGE to differ between organic and 346 conventionally produced crops. Llano et al. (2018) demonstrated that an untargeted 347 metabolomics approach was able to identify metabolites (biomarkers) that could 348 discriminate between organic and conventional goldenberry fruit.

\section{Conclusion}


One of the challenges of additional supply chain risk assessment processes and verification steps is that this can add quality cost to the supply chain but it is a preventative cost that will offset the costs of a recall. Risk assessment processes for food fraud include the use of threat analysis critical control point (TACCP) and vulnerability analysis critical control point (VACCP). However, only known and assessable threats can be prioritised (using a semi-quantitative assessment of likelihood and severity) to then develop a control measure(s) (countermeasure) and then a subjective scoring system to identify CCPs. Then effective fraud risk management, monitoring and verification systems can be developed. However the binary aspect of known/unknown threats means that decision-makers may then identify a subsequent incident that could lead to a major food recall as simply being "unforeseeable" (Manning, in press).

Since the Elliott Review, the notion of food integrity has been developing not just in terms of the product itself, but also the processes employed, the behaviour of individuals and the validity of data that is being used (Manning, 2016). This growing interest in integrity has led to the emergence of new techniques to confirm origin, variety and method of production e.g. organic or conventional. Indeed, metabolomics is enabling metabolite fingerprinting which is showing the potential to discriminate between a range of production factors. Further studies will require large numbers of samples to be taken, analysed and the results included in reference databases. These will need to encompass a wide range of sources of variation for the target biomarkers i.e. different agronomic conditions, vegetable varieties and geographical locations (Bueno et al. 2018). Nontargeted metabolomics utilized in metabolite fingerprinting can generate very large datasets, requiring bioinformatics analysis and increasingly machine learning (Medina et al. 2019). These developments are of value in determining the potential for mislabelling and mis-description, and effective verification protocols combining product and process 
verification need to be developed and effectively implemented in order to maintain

376 consumer trust in the fresh produce industry.

377

378

379

380

\section{References}

381

382

Ahumada, O. and Villalobos, J.R. (2009). A tactical model for planning the production 383 and distribution of fresh produce, Annals of Operations Research, 190(1), 39-58.

384

385

Albersmeier, F., Schulze, H., Jahn, G., and Spiller, A. (2009), The reliability of thirdparty certification in the food chain: From checklists to risk-oriented auditing, Food

387 Control, 20(10), 927-935

388

389

Bigot, C., Meile, J. C., Kapitan, A., and Montet, D. (2015). Discriminating organic and conventional foods by analysis of their microbial ecology: An application on fruits. Food control, 48, 123-129.

393 Ballin, N.Z. and Laursen, K.H., (2018). To target or not to target? Definitions and nomenclature for targeted versus non-targeted analytical food authentication. Trends in

Food Science \& Technology. Available at: https://doi.org/10.1016/j.tifs.2018.09.025

397 Bat, K. B., Vodopivec, B. M., Eler, K., Ogrinc, N., Mulič, I., Masuero, D., and

398 Vrhovšek, U. (2018). Primary and secondary metabolites as a tool for differentiation of apple juice according to cultivar and geographical origin. LWT, 90, 238-245.

400 
Bateman, A. and Cottrill, K. (2017). Blockchain's Garbage In, Garbage Out Challenge.

402 Available at: https://supplychainmit.com/2017/10/19/blockchains-garbage-in-garbage-

Bertolini, M., Bevilacqua, M., and Massini, R. (2006), FMECA approach to product London.

BS EN ISO 22000: 2005, 'Food safety management systems - requirements for any organization in the food chain', BSI London.

BS EN ISO 9001: 2015 Quality management systems: requirements. TSO London

417 Bueno, M.J.M., Díaz-Galiano, F.J., Rajski, Ł., Cutillas, V. and Fernández-Alba, A.R., 418 (2018). A non-targeted metabolomic approach to identify food markers to support 419 discrimination between organic and conventional tomato crops. Journal of 420 Chromatography A, 1546, 66-76.

422 Capuano, E., Boerrigter-Eenling, R., van der Veer, G. and van Ruth, S.M., (2013). 423 Analytical authentication of organic products: an overview of markers. Journal of the Science of Food and Agriculture, 93(1), 12-28. 
Carter, C., Krissoff, B. and Zwane, A.P., (2006). Can Country-of-Origin Labeling

Succeed as a Marketing Tool for Produce? Lessons from Three Case Studies. Canadian

Journal of Agricultural Economics/Revue canadienne d'agroeconomie, 54(4), 513-530.

429

430 Cubero-Leon, E., Peñalver, R. and Maquet, A., (2014). Review on metabolomics for food authentication. Food Research International, 60, 95-107.

432

Dabbene, F., Gay, P. and Tortia, C. (2014), Traceability issues in food supply chain management: A review, Biosystems Engineering, 120, 65-80

Danezis, G.P., Tsagkaris, A.S., Brusic, V. and Georgiou, C.A., (2016). Food authentication: state of the art and prospects. Current Opinion in Food Science, 10, 2231.

EC/178/2002 laying down the general principles and requirements of food safety law, establishing the European Food Standards Agency and laying down procedures in matters of food safety OJ L/31 1.2.2002 pp. $001-024$

444 Eckersley, N. (2011), Coles and Woolies in false fruit labelling pickle. Available at: https://www.thepacker.com/article/canadian-company-fined-mislabeling-mexicanproduce $\{$ Accessed 28 November 2018]

448 Elliott Review. (2014). Elliott Review into the integrity and assurance of food supply 449 networks - final report a national food crime prevention framework. HM Government July 2014. London. 
452 Esslinger, S., Riedl, J. and Fauhl-Hassek, C., (2014). Potential and limitations of non-

453 targeted fingerprinting for authentication of food in official control. Food Research 454 International, 60, 189-204.

455

456 EU 1151/2012 (2012). Regulation (EU) No 1151/2012 of the European Parliament and 457 of the Council of 21 November 2012 on quality schemes for agricultural products and 458 foodstuffs. Available at: $\quad$ http://eur-lex.europa.eu/legalcontent/EN/TXT/?uri=CELEX\%3A32012R1151 (Accessed $10^{\text {th }}$ November 2018)

460

461 European Food Safety Authority (EFSA). 2013. Scientific opinion on the risk posed by 462 pathogens in food of non-animal origin, part 1. Outbreak data analysis and risk ranking 463 of food/pathogen combinations. EFSA Journal. 11, 3025.

464

465 Faour-Klingbeil, D. and Todd, E., (2018). A Review on the Rising Prevalence of 466 International Standards: Threats or Opportunities for the Agri-Food Produce Sector in 467 Developing Countries, with a Focus on Examples from the MENA Region. Foods, 7(3), $468 \quad 33-56$.

469

470 Feldmann, C. and Hamm, U., (2015). Consumers' perceptions and preferences for local 471 food: A review. Food Quality and Preference, 40, 152-164.

472

473 Flores, P., López, A., Fenoll, J., Hellín, P. and Kelly, S., (2013). Classification of organic 474 and conventional sweet peppers and lettuce using a combination of isotopic and bio475 markers with multivariate analysis. Journal of food composition and analysis, 31(2), 217476225. 
478 Gil, M. I., M. V. Selma, T. Suslow, L. Jacxsens, M. Uyttendaele, and A. Allende. (2015).

479 Pre- and postharvest preventive measures and intervention strategies to control microbial 480 food safety hazards of fresh leafy vegetables. Crit. Rev. Food Sci. Nutr. 55, 453-468.

482 Goddard, E., Muringai, V., and Boaitey, A. 2018. Food Integrity and Food Technology

483 Concerns in Canada: Evidence from Two Public Surveys. Journal of Food Quality, 4842018.

485

486 Govt.uk 2019. Marketing standards for fresh fruit and vegetables. Available at:

487 https://www.gov.uk/guidance/comply-with-marketing-standards-for-fresh-fruit-and-

$488 \quad$ vegetables [Accessed 12 January 2019]

489

490 Gundersen, V., Bechmann, I. E., Behrens, A., and Stürup, S. (2000). Comparative 491 investigation of concentrations of major and trace elements in organic and conventional 492 Danish agricultural crops. 1. Onions (Allium c epa Hysam) and Peas (Pisum s ativum 493 Ping Pong). Journal of Agricultural and Food Chemistry, 48(12), 6094-6102.

494

495 Hollands, T. Martindale, W, Swainson, M and Keogh, J.G (2018), Blockchain or bust for 496 the food industry. Food Science and Technology Journal. Available at: 497 https://www.fstjournal.org/features/32-4/blockchain [Accessed 14 January 2019]

498 Inácio, C.T., Chalk, P.M. and Magalhães, A.M., (2015). Principles and limitations of 499 stable isotopes in differentiating organic and conventional foodstuffs: 1. Plant products. 500 Critical reviews in food science and nutrition, 55(9), 1206-1218. 
502 Jacxsens, L., Luning, P.A., Van der Vorst, J.G.A.J., Devlieghere, F., Leemans, R. and

503 Uyttendaele, M., (2010). Simulation modelling and risk assessment as tools to identify

504 the impact of climate change on microbiological food safety-The case study of fresh

505 produce supply chain. Food Research International, 43(7), 1925-1935.

506

507 Joyce, T. (2014), Cypriots furious at mislabelling, Available at:

508 http://www.fruitnet.com/eurofruit/article/162635/cypriots-react-angrily-to-mislabelling

509 [Accessed 28 November 2018]

510

511 Karst, T. (2018), Canadian company fined for mislabelling Mexican produce, Available

512 at: https://www.thepacker.com/article/canadian-company-fined-mislabeling-mexican-

513 produce [Accessed 28 November 2018]

514

515 Kelly, S. D., and Bateman, A. S. (2010). Comparison of mineral concentrations in

516 commercially grown organic and conventional crops-Tomatoes (Lycopersicon

517 esculentum) and lettuces (Lactuca sativa). Food Chemistry, 119(2), 738-745.

518

519 Kleboth, J.A., Luning P. A. Fogliano, V. 2016. Risk-based integrity audits in the food

520 chain - A framework for complex systems, Trends in Food Science \& Technology, 56,

$521 \quad 167-174$.

522

523 Kleter, G. A., and Marvin, H.J.P. (2009). Indicators of emerging hazards and risks to food 524 safety. Food and Chemical Toxicology, 47, 1022-1039. 
526 Kowalska, A., Soon, J.M. and Manning, L. (2018). A study on adulteration in cereals and 527 bakery products from Poland including a review of definitions. Food Control, 92, 348356

529

530 Khursheed, A., Kumar, M., and Sharma, M. (2016) Security Against Cyber Attacks in 531 Food Industry. International Journal of Control Theory and Applications, 9(17) 2016, pp. $8623-8628$

533

534 Laursen, K.H., Mihailova, A., Kelly, S.D., Epov, V.N., Bérail, S., Schjørring, J.K.,

535 Donard, O.F.X., Larsen, E.H., Pedentchouk, N., Marca-Bell, A.D. and Halekoh, U., 2013.

536 Is it really organic?-Multi-isotopic analysis as a tool to discriminate between organic and 537 conventional plants. Food Chemistry, 141(3), 2812-2820.

538

539 Laursen, K.H., Schjørring, J.K., Kelly, S.D. and Husted, S., 2014. Authentication of 540 organically grown plants-advantages and limitations of atomic spectroscopy for multi541 element and stable isotope analysis. TrAC Trends in Analytical Chemistry, 59, 73-82.

543 Liu, C., Qi, X., Song, L., Li, Y., and Li, M. (2018). Species identification, genetic 544 diversity and population structure of sweet cherry commercial cultivars assessed by SSRs 545 and the gametophytic self-incompatibility locus. Scientia Horticulturae, 237, 28-35.

547 Llano, S.M., Muñoz-Jiménez, A.M., Jiménez-Cartagena, C., Londoño-Londoño, J. and 548 Medina, S., (2018). Untargeted metabolomics reveals specific withanolides and fatty acyl 549 glycoside as tentative metabolites to differentiate organic and conventional Physalis 550 peruviana fruits. Food Chemistry, 244,120-127 
552 Manning, L. (in press). Food defence: refining the taxonomy of food defence threats, 553 Trends in Food Science and Technology.

554 Manning, L. (2018). Food supply chain fraud: the economic, environmental and socio-

555 political consequences. In Barling, D., and Fanzo, J. Eds. Advances in Food Security

556 and Sustainability (Vol. 3). Academic Press.

557

558 Manning, L. and Wareing, P. (2018), Evolving risk management systems, Food Science 559 and Technology Journal IFST, Available at https://www.fstjournal.org/features/32-

560 3/risk-management-systems [Accessed 01 November 2018]

561

562 Manning, L. Soon. J.M., Aguiar, L.K., Eastham, J.F., and Higashi, S.Y. (2017)

563 Pressure: driving illicit behaviour in the food supply chain 12th Research Workshop on

564 Institutions and Organisations (12th RWIO) Brazil 10-11 July 2017

565

566 Manning, L. (2017), Traceability: An essential mechanism to underpin food integrity. In

567 Eastham et al. Contemporary issues in food supply chain management. Goodfellow

568 Publishers Ltd. ISBN: 9781911396093

569

570 Manning L. (2016). Food fraud, policy and food chain, Current Opinions in Food 571 Science, 10, 16-21.

572

573 Manning, L., and Soon, J. M. (2014). Developing systems to control food 574 adulteration. Food Policy, 49, 23-32. 
576 Martinez, M. G., Verbruggen, P., and Fearne, A. (2013). Risk-based approaches to food

577 safety regulation: What role for co-regulation? Journal of Risk Research, 16, 11015781121.

579

580 Marvin, H. J., Bouzembrak, Y., Janssen, E. M., van der Fels-Klerx, H. J., van Asselt, E. 581 D., and Kleter, G. A. (2016). A holistic approach to food safety risks: Food fraud as an 582 example. Food Research International, 89, 463-470.

583

584 McDonald's Corporation. 2012. McDonald's good agricultural practices food safety 585 standards, food safety checklist \& produce processing guidelines. August 2012. 586 McDonald's Corporation, Oak Brook, IL.

587

588 Medina, S., Pereira, J.A., Silva, P., Perestrelo, R. and Câmara, J.S., (2019). Food 589 fingerprints-A valuable tool to monitor food authenticity and safety. Food Chemistry. $590 \quad 278,144-162$

592 Mihailova, A., Pedentchouk, N. and Kelly, S.D., 2014. Stable isotope analysis of plantderived nitrate-novel method for discrimination between organically and conventionally grown vegetables. Food chemistry, 154, 238-245.

Monaghan, J.M., Augustin, J.C., Bassett, J., Betts, R., Pourkomailian, B. and Zwietering, 597 M.H., (2016). Risk assessment or assessment of risk? Developing an evidence-based approach for primary producers of leafy vegetables to assess and manage microbial risks. Journal of food protection, 80(5), 725-733.

600 
601 Perini, M., Giongo, L., Grisenti, M., Bontempo, L., and Camin, F. (2018). Stable isotope

602 ratio analysis of different European raspberries, blackberries, blueberries, currants and 603 strawberries. Food chemistry, 239, 48-55.

604

605 Picchi, V., Migliori, C., Scalzo, R. L., Campanelli, G., Ferrari, V., and Di Cesare, L. F. 606 (2012). Phytochemical content in organic and conventionally grown Italian 607 cauliflower. Food Chemistry, 130(3), 501-509.

608

609 Powell, D.A., Erdozain, S., Dodd, C., Costa, R., Morley, K. and Chapman, B.J., (2013).

610 Audits and inspections are never enough: a critique to enhance food safety. Food

611 Control, 30(2), 686-691.

612

613 Primrose, S., Woolfe, M., and Rollinson, S. (2010). Food forensics: methods for

614 determining the authenticity of foodstuffs. Trends in Food Science and Technology, $615 \quad 21(12), 582-590$.

616

617 Pustjens, A. M., Weesepoel, Y., and van Ruth, S. M. 2016. Food fraud and authenticity: 618 emerging issues and future trends. In Innovation and future trends in food manufacturing 619 and supply chain technologies (pp. 3-20).

620

621 RASFF. nd. RASFF - Food and Feed Safety Alerts. Available at: 622 https://ec.europa.eu/food/safety/rasff_en [Accessed 12 January 2019]

623 
624 Rossetto, M. R. M., Shiga, T. M., Vianello, F., and Lima, G. P. P. (2013). Analysis of 625 total glucosinolates and chromatographically purified benzylglucosinolate in organic and 626 conventional vegetables. LWT-Food Science and Technology, 50(1), 247-252.

627

628 RTA (2017) Red Tractor Assurance for Farms - Fresh Produce Standards version 4.1.

629 Updated October 2018. Available from: https://assurance.redtractor.org.uk/contentfiles/

$630 \quad$ Farmers-6825.pdf? $=636790163976612608$. [Accessed 30 October 2018].

631

632 Salama, K.F., Luzzatto, D., Sianesi, A. and Towill, D.R., (2009). The value of auditing 633 supply chains. International Journal of Production Economics, 119(1), 34-45.

634

635 Sarpong, S. (2014). Traceability and supply chain complexity: confronting the issues and 636 concerns. European Business Review, 26(3), 271-284.

637

638 Scarano, D., Rao, R., Masi, P. and Corrado, G., (2015). SSR fingerprint reveals 639 mislabeling in commercial processed tomato products. Food Control, 51, 397-401.

640

641 Schmidt, H.L., Roßmann, A., Voerkelius, S., Schnitzler, W.H., Georgi, M., Graßmann,

642 J., Zimmermann, G. and Winkler, R., (2005). Isotope characteristics of vegetables and 643 wheat from conventional and organic production. Isotopes in Environmental and Health 644 Studies, 41(3), 223-228.

645

646 El Sheikha, A.F., Condur, A., Métayer, I., Le Nguyen, D.D., Loiseau, G. and Montet, D., 647 (2009). Determination of fruit origin by using 26S rDNA fingerprinting of yeast 
648 communities by PCR-DGGE: preliminary application to Physalis fruits from Egypt. 649 Yeast, 26(10), 567-573.

650

651 Shukla, M. and Jharkharia, S., (2013). Agri-fresh produce supply chain management: a 652 state-of-the-art literature review. International Journal of Operations \& Production 653 Management, 33(2), 114-158.

654

655

Soon, J. M., Manning, L., and Smith, R. (2019). Advancing understanding of pinch-points 656 and crime prevention in the food supply chain. Crime Prevention and Community Safety.

657

Stachniuk, A., (2018). LC-MS/MS determination of pesticide residues in fruits and 659 vegetables. Bioactive Molecules in Food, 1-26.

660

661 Thakur, M. and Hurburgh, C.R. (2009), Framework for implementing traceability 662 system in the bulk grain supply chain, Journal of Food Engineering, 95, 617-626

663

664 Vallverdú-Queralt, A., Medina-Remón, A., Casals-Ribes, I., and Lamuela-Raventos, R. 665 M. (2012). Is there any difference between the phenolic content of organic and 666 conventional tomato juices? Food Chemistry, 130(1), 222-227.

667

668 Verbruggen, P., and Havinga, T. (2015). Food safety meta-controls in The Netherlands.

669 European Journal of Risk Regulation, 6, 512-524.

670

671 Woolfe, M. and Primrose, S., (2004). Food forensics: using DNA technology to combat 672 misdescription and fraud. Trends in Biotechnology, 22(5), 222-226. 
674 Yuan, Y., Hu, G., Chen, T., Zhao, M., Zhang, Y., Li, Y., Xu, X., Shao, S., Zhu, J., Wang, 675 Q. and Rogers, K.M., (2016). Improved discrimination for Brassica vegetables treated 676 with agricultural fertilizers using a combined chemometric approach. Journal of 677 agricultural and food chemistry, 64(28), 5633-5643.

678

679

680 
681

682 Table 1. Factors that influence fresh produce supply chains (Adapted from 683 Ahumada and Villabos, 2009; Shukla and Jharkharia, 2013).

684

\begin{tabular}{|c|c|c|}
\hline Strategic & Tactical & Operational \\
\hline Financial planning & Harvest planning & Production scheduling activities \\
\hline $\begin{array}{l}\text { Demand forecasting } \\
\text { accuracy and modelling }\end{array}$ & Crop choice & Harvesting \\
\hline $\begin{array}{l}\text { Capacity (warehouse and } \\
\text { production facilities) }\end{array}$ & Crop scheduling & Storage \\
\hline $\begin{array}{l}\text { Supply network design } \\
\text { Technology }\end{array}$ & $\begin{array}{l}\text { Logistics and } \\
\text { transportation }\end{array}$ & Transportation (vehicle routing) \\
\hline \multirow[t]{3}{*}{ Demand-price elasticity } & $\begin{array}{l}\text { Inventory } \\
\text { management }\end{array}$ & Weather conditions \\
\hline & Labour selection & Plant maturation rates \\
\hline & & $\begin{array}{l}\text { Product shelf-life/rate of } \\
\text { deterioration }\end{array}$ \\
\hline
\end{tabular}

685

686 


\begin{tabular}{|l|l|}
\hline Case & Details \\
\hline Case 1 & $\begin{array}{l}\text { Vidalia spring onions (Georgia United States) have a premium price } \\
\text { compared to product from other US states. 1986 saw state legislation to } \\
\text { delignate a specific production area. Additional quality control systems } \\
\text { were put in place. Incidences of rebagging occurred. Between 2001 and } \\
\text { 2003 there were six fines ranging from \$5,000 to \$29,000 for misuse of } \\
\text { Vidalia label. A further case fine was \$100,000. (Carter et al. 2006) }\end{array}$ \\
\hline Case 2 & $\begin{array}{l}\text { The "San Marzano" tomato is one of the most important processing tomato } \\
\text { varieties in the world. The tomato has a designated origin but is often } \\
\text { substituted with other plum tomatoes from both Italy and outside Italy } \\
\text { leading to deception of consumers (Scarano et al. 2015). }\end{array}$ \\
\hline Case 3 & $\begin{array}{l}\text { The labelling of Greek produce as Cypriot when there was oversupply of } \\
\text { Greek product due to the Russian embargo in 2014 (Joyce, 2014) }\end{array}$ \\
\hline Case 4 & $\begin{array}{l}\text { A Canadian company AMCO Produce was fined \$210,000 in 2018 by the } \\
\text { Canadian Food Insepction Agency (CFIA) because between 2012 and } \\
\text { 2014, the company was said to have intentionally mislabelled produce, } \\
\text { including tomatoes and cucumbers, as being from Canada when the } \\
\text { country of origin was in fact Mexico. The products were sold to Sobeys } \\
\text { Inc. and other retailers. The CFIA undertook a random inspection and } \\
\text { found products labelled as Ontario produce when in February the } \\
\text { temperatures were too low in the region for greenhouse production (Karst, } \\
\text { 2018). }\end{array}$ \\
\hline Case 5 & $\begin{array}{l}\text { Australian Supermarkets Coles and Woolworths were fined in 2011 when } \\
\text { two stores were identified as selling mislabelled fruit - one for not } \\
\text { declaring the country of origin and the other store for selling lemons } \\
\text { origination from the USA as "Product of Australia" (Eckersley, 2011). }\end{array}$ \\
\hline
\end{tabular}

